\title{
ANALISIS FAKTOR-FAKTOR YANG MEMPENGARUHI PRODUKSI BIOGAS DARI LIMBAH TERNAK DI KEC. BAROKO KAB. ENREKANG
}

\author{
Jumadi Tangko ${ }^{1}$, Sonong ${ }^{1}$, Muh. Andi Chaerul S ${ }^{2}$, dan Junaidi Salam ${ }^{2}$
}

\begin{abstract}
Abstrack: Penelitian ini dilakukan yaitu untuk mengetahui/menganalisa faktor-faktor apa saja yang dapat mempengaruhi produksi biogas limbah ternak sapi didalam sebuah digester, dimana ukuran digester yang digunakan yaitu dengan diameter digester $\pm 2 \mathrm{~m}$ dan tinggi $\pm 2 \mathrm{~m}$. Penelitian ini dilakukan di Kecamatan Baroko Kabupaten Enrekang, menggunakan metode eksperimental dengan perlakuan penambahan subtrat seperti Em4 kedalam campuran kotoran sapi dengan air dan dengan melakukan perbandingan 1:2 dimana kotoran sapi lebih sedikit daripada air. Dalam penelitian ini penulis menggunakan alat ukur manometer $U$, Ph-meter dan Penelitian ini bertujuan untuk mengetahui pengaruh penambahan Em4 dan perbandingan 1:2 terhadap produksi biogas di Kecamatan Baroko Kabupaten Enrekang. Hasil pengujian yang dilakukan menunjukkan bahwa penambahan Em4 dapat meningkatkan peroduksi biogas dimana tekanan tertinggi terjadi pada hari ke-6 dengan kenaikan tekanan mencapai $31.5 \mathrm{~cm}$ (kenaikan presure di malam hari). Sedangkan perbandingan 1:2 hasil penelitian menunjukkan adanya penurunan produksi biogas. Hal ini dikarenakan kurangnya sumber makanan bagi bakteri-bakteri pembentuk biogas.
\end{abstract}

Kata kunci: biogas, EM4, perbandingan 1:2

\section{PENDAHULUAN}

Kebutuhan energi semakin lama semakin meningkat sebagai mana laju pertambahan penduduk. Hal ini mendorong pemerintah untuk melakukan berbagai upaya seperti import gas, pemakaian sumber daya alternatif, dan sebagainya (Hermawan, 2014). Salah satu upaya yang telah dilakukan yaitu pengembangan sistem biogas dari kotoran hewan ternak seperti sapi, kambing, ayam, dan lain-lain. Biogas adalah gas produk akhir pencernaan/degradasi anaerobik (dalam lingkungan tanpa oksigen) oleh bakteri-bakteri menthanogen.

Salah satu limbah yang dihasilkan dari aktifitas kehidupan manusia adalah limbah dari usaha peternakan sapi yang terdiri dari feses, urin, gas dan sisa makanan ternak. Potensi limbah peternakan sebagai salah satu bahan baku pembuatan biogas dapat ditemukan disentra-sentra peternakan, terutama dipeternakan dengan skala besar yang menghasilkan limbah dalam jumlah besar dan rutin. Kabupaten Enrekang di Provinsi SULSEL terkenal dengan potensi peternakan. Beberapa daerah yang ada di Kab. Enrekang memiliki potensi ternak.

Salah satu daerah yang memiliki potensi ternak yaitu berada di Desa Bonco kec. Baroko. Dimana daerah tersebut memiliki jumlah ternak sapi yang begitu banyak. Dengan melihat kondisi tersebut Desa Bonco kec. Baroko dapat memanfaatkan kotoran ternak tersebut dengan mengolah kotoran sapi menjadi biogas.

Proses pembentukan biogas di bantu oleh mikroorganisme bakteri pembusuk dan bakteri penghasil metan. Dalam proses pembuatan biogas ini menggunakan dua tahap fermentasi, yaitu fermentasi aerob dan fermentasi anaerob. Dalam proses fermentasi aerob akan dihasilkan asam-asam organik seperti asam asetat dan energi yang digunakan oleh bakteri metanogen pada proses aneorob sehingga menghasilkan gas metan yang lebih cepat. Dalam proses pembentukan biogas terkadang mengalami penghambatan/peningkatan produksi, hal ini dikarenakan oleh beberapa faktor, diantaranya adalah suhu/temperatur, $\mathrm{pH}$, serta adanya penambahan substrat dan lain -lain.

\section{METODE PENELITIAN}

\footnotetext{
${ }^{1}$ Staf Pengajar D4 Jurusan Teknik Mesin Politeknik Negeri Ujung Pandang

${ }^{2}$ Alumni Program D4 Jurusan Teknik Mesin Politeknik Negeri Ujung Pandang
} 
Penelitian ini dilakukan di Kecamatan Baroko Kabupaten Enrekang atau lebih teparnya dirumah keluarga pak rahim dan keluarga, proses pembuatan komponen-komponen biogas limbah ternak dilakukan selama +1 bulan, sedangkan waktu pelaksanaan penelitian dilakukan selama 3 minggu mulai dari tanggal 5 -24 september 2017.

\section{A. Alat dan Bahan}

\begin{tabular}{|c|c|c|}
\hline No & Alat dan bahan & Jumlah \\
\hline 1 & Pasir & 2 mobil truck \\
\hline 2 & Batu bata & \pm 1000 batu bata \\
\hline 3 & Semen & 17 sak \\
\hline 4 & Pipa 3 inci & 3 buah \\
\hline 5 & Pipa $1 / 2$ & 2 buah \\
\hline 6 & Kran air & \\
\hline 7 & Besiah \\
\hline 8 & Lem pipa & 1 buah \\
\hline 9 & Sambungan pipa (L) $1 / 2$ inci & 5 buah \\
\hline 10 & Sambungan pipa (lurus) $1 / 2$ inci & 6 buah \\
\hline 11 & Lem silikon & 1 buah \\
\hline 12 & Geregaji pipa & 1 buah \\
\hline 13 & Sambungan pipa (L) 2 inci & 1 buah \\
\hline 14 & Pipa 2 inci & 1 buah \\
\hline
\end{tabular}

\section{B. Prosedur Penelitian}

Prosedure pada penelitian ini dilakukakan 2 tahap penelitian yaitu tahap penelitian perbandingan air dengan kotoran sapi $(1: 1,2: 1$, dan 1:1,5) dan penambahan biofaktor EM4 (1 botol, 1,5 botol, dan 2 botol). pada saat pengambilan data selanjutnya dilakukan pembocoran gas pada pipa pembuangan air selama 1 hari.

$>$ Untuk perbandingan air dengan kotoran sapi

a. Pertama, mengukur tekanan biogas, $\mathrm{pH}$ yang dihasilkan sebelum melakukan penelitian selama 15 hari.

b. Setelah 15 hari, tahap Selanjutnya adalah mencampurkan kotoran sapi dengan air dengan perbandingan $(1: 1,2: 1$, dan $1: 1,5)$, campuran tersebut dimasukkan kedalam mixer pencampur.

c. Lalu memasukkan bahan kedalam digester.

d. Kemudian langkah selanjutnya adalah, melakukanpengukuran $\mathrm{Ph}$ dan tekanan gas yang dihasilkan selama 9 hari.

e. Mencatat data hasil pengukuran tekanan gas dan $\mathrm{pH}$.

f. Membuat grafik analisa data.

g. Tahap terakhir, melakukan analisa data dan membuat kesimpulan

$>$ Untuk penambahan biofaktor EM4

a. Pertama, masukkan bahan baku kedalam ember dengan perbandingan 1:1

b. Selanjutnya, memasukkan bahan baku kotoran sapi dan air kedalam bak pengaduk untuk diencerkan dan alirkan/masukkan kedalam digester dan campurkan dengan EM4 (1 botol, 1,5 botol dan 2 botol) dan masukkan kedalam digester.

c. Setiap selama 9 hari ,langkah selanjutnya adalah melakukanpengukuran $\mathrm{Ph}$ dan tekanan gas yang dihasilkan setiap harinya.

d. Mencatat data hasil pengukuran tekanan gas dan $\mathrm{pH}$.

e. Membuat grafik.

f. Tahap terakhir, melakukan analisa pada grafik dan membuat kesimpulan.

\section{Teknik Analisis Data}


65 Jumadi Tangko, Sonong, Muh. Andi Chaerul S, Junaidi Salam. Analisis Faktor-Faktor Yang Mempengaruhi Produksi Biogas Dari Limbah Ternak Di Kec. Baroko Kab. Enrekang

Teknik menganalisa data pada tugas akhir ini sebagaimana telah dijelaskan sebelumnya bahwa metode yang digunakan dalam penelitian ini untuk mengumpulkan data yaitu studi pustaka, observasi, perancangan, pembuatan komponen bagunan biogas, pengujian dan pengambilan data. Setelah semua data yang diperoleh, selanjutnya data tersebut dihitung berdasarkan perhitungan yang telah ditentukan.

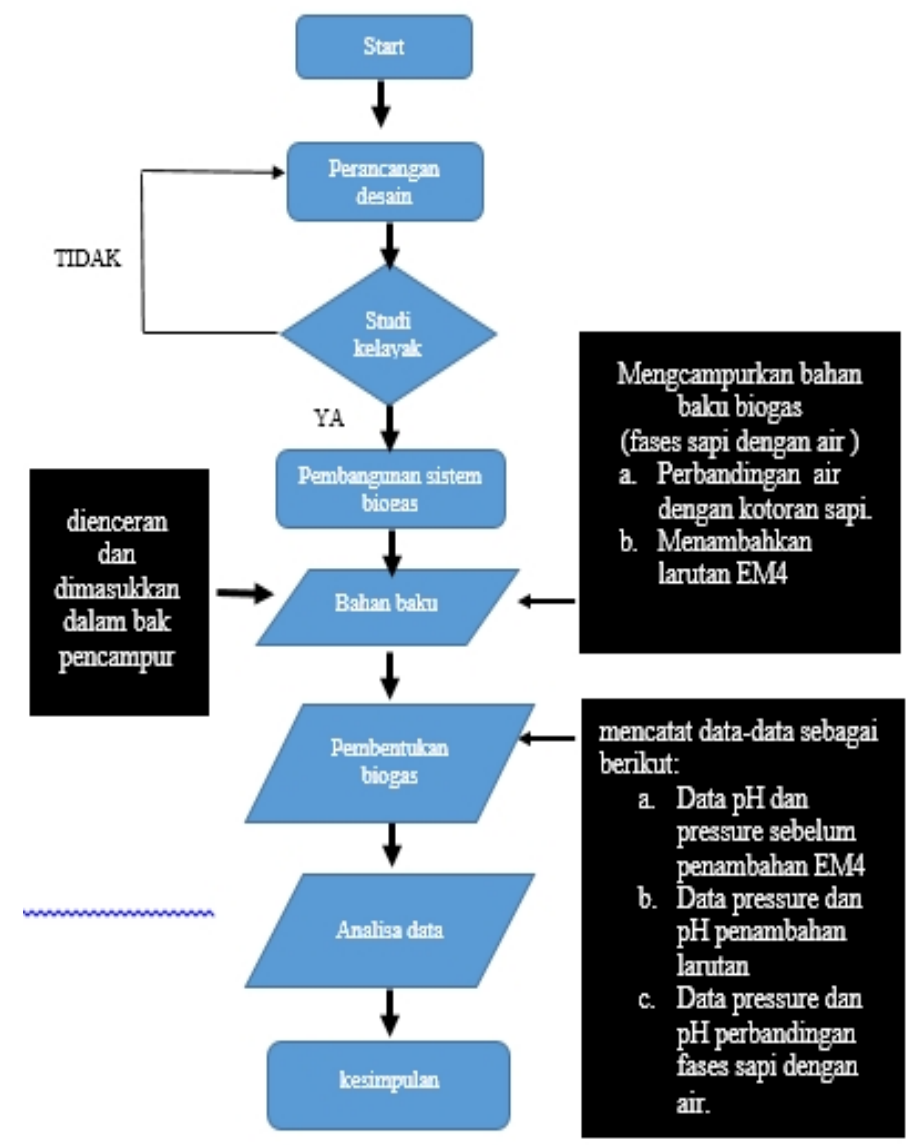

Gambar 1. Diagram Alir Penelitian

\section{HASIL DAN PEMBAHASAN}

\section{A. Data Hasil Penelitia}

Setelah prosedur penelitian dan pengambilan data dilakukan, maka diperoleh data-data variable faktor-faktor yang mempengaruhi produksi biogas sebagai berikut:

Tabel 1. Data pressure dalam manometer $U$ pada masa pembentukan biogas perbandingan air dan kotoran sapi dengan perbandingan 1:1.

\begin{tabular}{|c|c|c|c|c|c|}
\hline Hari & $\begin{array}{c}\text { Pressure Manometer } \mathrm{U} \\
\left(\mathrm{Cm} \mathrm{H}_{2} \mathrm{O}\right)\end{array}$ & $\begin{array}{c}\Lambda \mathrm{P} \\
\left(\mathrm{Cm} \mathrm{H}_{2} \mathrm{O}\right)\end{array}$ & $\begin{array}{c}\text { Suhu Digester } \\
\left({ }^{\circ} \mathrm{c}\right)\end{array}$ & $\mathbf{P h}$ & Ket. \\
\hline 1 & $35-35$ & 0 & $22^{\circ} \mathrm{c}$ & 4,7 & Belum berbau gas \\
\hline 2 & $35-35$ & 0 & $22,6^{\circ} \mathrm{c}$ & 4,7 & Belum berbau gas \\
\hline 3 & $35-35$ & 0 & $22,3^{\circ} \mathrm{c}$ & 4,7 & Belum berbau gas \\
\hline 4 & $35-35$ & 0 & $24,4^{\circ} \mathrm{C}$ & 4,7 & Belum berbau gas \\
\hline 5 & $35-35$ & 0 & $21,5^{\circ} \mathrm{c}$ & 4,7 & Belum berbau gas \\
\hline 6 & $35-35$ & 0 & $22,{ }^{\circ} \mathrm{c}$ & 4,7 & Belum berbau gas \\
\hline 7 & $35-35$ & 0 & $20,2^{\circ} \mathrm{C}$ & 4,7 & Belum berbau gas \\
\hline 8 & $35-35$ & 0 & $20,4^{\circ} \mathrm{C}$ & 4,7 & Belum berbau gas \\
\hline 9 & $35-35$ & 0 & $20,8^{\circ} \mathrm{C}$ & 4,8 & Belum berbau gas \\
\hline 10 & $35-35$ & 0 & $21,5^{\circ} \mathrm{c}$ & 4,8 & Belum berbau gas \\
\hline 11 & $35-35$ & 0 & $23,7^{\circ} \mathrm{c}$ & 4,8 & Sudah ada bau gas \\
\hline
\end{tabular}




\begin{tabular}{|c|c|c|c|c|c|}
\hline 12 & $35-35$ & 0 & $23,3^{\circ} \mathrm{c}$ & 4,8 & Sudah ada bau gas \\
\hline 13 & $35-35$ & 0 & $23,4^{\circ} \mathrm{C}$ & 4,8 & Sudah ada bau gas \\
\hline 14 & $34,8-35,2$ & 0.4 & $25^{\circ} \mathrm{C}$ & 4,8 & Sudah mengalami perubahan kenaikan tekanan gas \\
\hline 15 & $33,3-36,7$ & 3.4 & $23^{\circ} \mathrm{C}$ & 4,8 & Sudah mengalami perubahan kenaikan gas \\
\hline
\end{tabular}

Tabel 2. Data pressure dalam manometr $U$ perbandingan 1:1 (air dengan fases sapi).

\begin{tabular}{|c|c|c|c|c|c|}
\hline Hari & $\begin{array}{c}\text { Pressure Manometer U } \\
\left(\mathrm{CmH}_{2} \mathrm{O}\right)\end{array}$ & $\begin{array}{c}\Lambda \mathbf{P} \\
\left(\mathrm{Cm} H_{2} \mathrm{O}\right)\end{array}$ & $\begin{array}{c}\text { Suhu Digester } \\
\left({ }^{\circ} \mathrm{c}\right)\end{array}$ & $\mathbf{P h}$ & Ket. \\
\hline 1 & $35-35$ & 0 & $22^{\circ} \mathrm{C}$ & 4,8 & Belum berbau gas \\
\hline 2 & $35-35$ & 0 & $24,2^{\circ} \mathrm{c}$ & 4,8 & Belum berbau gas \\
\hline 3 & $35-35$ & 0 & $20.6^{\circ} \mathrm{c}$ & 4,8 & Belum berbau gas \\
\hline 4 & $35-35$ & 0 & $23^{\circ} \mathrm{c}$ & 4,8 & Belum berbau gas \\
\hline 5 & $35-35$ & 0 & $23,8^{\circ} \mathrm{c}$ & 5 & Belum berbau gas \\
\hline 6 & $35-35$ & 0 & $23,3^{\circ} \mathrm{C}$ & 5 & Sudah ada bau gas \\
\hline 7 & $35-35$ & 0 & $22^{\circ} \mathrm{c}$ & 5 & Sudah ada bau gas \\
\hline 8 & $35-35$ & 0 & $24^{\circ} \mathrm{c}$ & 5 & Sudah ada bau gas \\
\hline 9 & $35-35$ & 0 & $23,5^{\circ} \mathrm{c}$ & 5 & Sudah ada bau gas \\
\hline
\end{tabular}

Tabel 3. Data pressure dalam manometr $U$ perbandingan 2:1 (air dengan fases sapi).

\begin{tabular}{|c|c|c|c|c|c|}
\hline Hari & $\begin{array}{c}\text { Pressure Manometer U } \\
\left(\mathrm{Cm} \mathrm{H}_{2} \mathrm{O}\right)\end{array}$ & $\begin{array}{c}\mathbf{A P} \\
\left(\mathrm{Cm} \mathrm{H}_{2} \mathrm{O}\right)\end{array}$ & $\begin{array}{c}\text { Suhu Digester } \\
\left({ }^{\circ} \mathrm{c}\right)\end{array}$ & $\mathbf{P h}$ & Ket. \\
\hline 1 & $35-35$ & 0 & $22^{\circ} \mathrm{C}$ & 5 & Belum berbau gas \\
\hline 2 & $35-35$ & 0 & $24,2^{\circ} \mathrm{C}$ & 5 & Belum berbau gas \\
\hline 3 & $35-35$ & 0 & $20.6^{\circ} \mathrm{c}$ & 5 & Belum berbau gas \\
\hline 4 & $35-35$ & 0 & $23^{\circ} \mathrm{C}$ & 5 & Sudah ada bau gas \\
\hline 5 & $35-35$ & 0 & $23,8^{\circ} \mathrm{C}$ & 5 & Sudah ada bau gas \\
\hline 6 & $35-35$ & 0 & $23,3^{\circ} \mathrm{C}$ & 5,2 & Sudah ada bau gas \\
\hline 7 & $35-35$ & 0 & $22^{\circ} \mathrm{C}$ & 5,2 & Sudah ada bau gas \\
\hline 8 & $29,2-40,8$ & 10,2 & $24^{\circ} \mathrm{C}$ & 5,2 & Sudah mengalami perubahan kenaikan tekanan gas \\
\hline 9 & $27,5-42,5$ & 15 & $23,5^{\circ} \mathrm{c}$ & 5,2 & Sudah mengalami perubahan kenaikan tekanan gas \\
\hline
\end{tabular}

Tabel 4. Data pressure dalam manometr $U$ perbandingan 1:1,5 (air dengan fases sapi).

\begin{tabular}{|c|c|c|c|c|c|}
\hline Hari & $\begin{array}{c}\text { Pressure Manometer } \mathbf{U} \\
\left(\mathbf{C} \mathbf{H}_{\mathbf{2}} \mathbf{O}\right)\end{array}$ & $\begin{array}{c}\mathbf{A} \mathbf{P} \\
\left(\mathbf{C m} \mathbf{H}_{\mathbf{2}} \mathbf{O}\right)\end{array}$ & $\begin{array}{c}\text { Suhu Digester } \\
\left.\mathbf{(}{ }^{\circ} \mathbf{c}\right)\end{array}$ & $\mathbf{P h}$ & Ket. \\
\hline 1 & $35-35$ & 0 & $23,3^{\circ} \mathrm{c}$ & 5,2 & Belum berbau gas \\
\hline 2 & $35-35$ & 0 & $22,4^{\circ} \mathrm{c}$ & 5,2 & Belum berbau gas \\
\hline 3 & $35-35$ & 0 & $22^{\circ} \mathrm{c}$ & 5,2 & Belum berbau gas \\
\hline 4 & $35-35$ & 0 & $22,2^{\circ} \mathrm{c}$ & 5,2 & Belum berbau gas \\
\hline 5 & $35-35$ & 0 & $22^{\circ} \mathrm{c}$ & 5,4 & Belum berbau gas \\
\hline 6 & $35-35$ & 0 & $23,4^{\circ} \mathrm{c}$ & 5,4 & Belum berbau gas \\
\hline 7 & $35-35$ & 0 & $23^{\circ} \mathrm{c}$ & 5,4 & Sudah ada bau gas \\
\hline 8 & $35-35$ & 0 & $23,6^{\circ} \mathrm{c}$ & 5,4 & Sudah ada bau gas \\
\hline 9 & $35-35$ & 0 & $23,5^{\circ} \mathrm{c}$ & 5,4 & Sudah ada bau gas \\
\hline
\end{tabular}

Tabel 5. Data pressure dalam manometr U setelah penambahan bioktivaktor Em4 sebanyak $500 \mathrm{ml}$.

\begin{tabular}{|c|c|c|c|c|c|}
\hline Hari & $\begin{array}{c}\text { Pressure Manometer U } \\
\left(\mathrm{Cm} \mathrm{H}_{2} \mathrm{O}\right)\end{array}$ & $\begin{array}{c}\Lambda \mathrm{P} \\
\left(\mathrm{Cm} \mathrm{H}_{2} \mathrm{O}\right)\end{array}$ & $\begin{array}{c}\text { Suhu Digester } \\
\left({ }^{\circ} \mathrm{c}\right)\end{array}$ & $\mathbf{P h}$ & Ket. \\
\hline 1 & $35-35$ & 0 & $22,4^{\circ} \mathrm{c}$ & 5,4 & Belum berbau, gas \\
\hline 2 & $35-35$ & 0 & $20,2^{\circ} \mathrm{c}$ & 5,4 & Belum berbau gas \\
\hline 3 & $35-35$ & 0 & $21,4^{\circ} \mathrm{C}$ & 5,4 & Belum berbau gas \\
\hline 4 & $35-35$ & 0 & $23,3^{\circ} \mathrm{C}$ & 5,4 & Belum berbau gas \\
\hline 5 & $35-35$ & 0 & $23^{\circ} \mathrm{c}$ & 5,4 & Sudah ada bau gas \\
\hline 6 & $35-35$ & 0 & $23^{\circ} \mathrm{c}$ & 5,4 & Sudah ada bau gas \\
\hline 7 & $32,6-37,5$ & 4,9 & $24,2^{\circ} \mathrm{C}$ & 5,5 & Sudah mengalami perubahan kenaikan tekanan gas \\
\hline
\end{tabular}


67 Jumadi Tangko, Sonong, Muh. Andi Chaerul S, Junaidi Salam. Analisis Faktor-Faktor Yang Mempengaruhi Produksi Biogas Dari Limbah Ternak Di Kec. Baroko Kab. Enrekang

\begin{tabular}{|c|c|c|c|c|l|}
\hline 8 & $28,7-41,3$ & 12,6 & $24,3^{\circ} \mathrm{c}$ & 5,5 & Sudah mengalami perubahan kenaikan tekanan gas \\
\hline 9 & $25,3-44,8$ & 19,5 & $22^{\circ} \mathrm{c}$ & 5,5 & Sudah mengalami perubahan kenaikan tekanan gas \\
\hline
\end{tabular}

Tabel 6. Data pressure dalam manometr U setelah penambahan bioktivaktor Em4 sebanyak $1000 \mathrm{ml}$.

\begin{tabular}{|c|c|c|c|c|c|}
\hline Hari & $\begin{array}{c}\text { Pressure Manometer } \\
\mathbf{U} \\
\left(\mathbf{C m} \mathbf{H}_{\mathbf{2}} \mathbf{O}\right)\end{array}$ & $\begin{array}{c}{ }_{\mathbf{A}} \mathbf{P} \\
\left(\mathbf{C} \mathbf{H}_{\mathbf{2}} \mathbf{O}\right)\end{array}$ & $\begin{array}{c}\text { Suhu } \\
\text { Digester } \\
\left({ }^{\circ} \mathbf{c}\right)\end{array}$ & $\mathbf{P h}$ & Ket. \\
\hline 1 & $35-35$ & 0 & $23,4^{\circ} \mathrm{c}$ & 5,7 & Belum berbau gas \\
\hline 2 & $35-35$ & 0 & $22,5^{\circ} \mathrm{c}$ & 5,7 & Belum berbau gas \\
\hline 3 & $35-35$ & 0 & $20^{\circ} \mathrm{c}$ & 5,7 & Belum berbau gas \\
\hline 4 & $35-35$ & 0 & $21,7^{\circ} \mathrm{c}$ & 5,7 & Sudah ada bau gas \\
\hline 5 & $34,2-36,8$ & 1.8 & $21,2^{\circ} \mathrm{c}$ & 5,7 & Sudah mengalami perubahan kenaikan tekanan gas \\
\hline 6 & $31,5-38,5$ & 7 & $20,8^{\circ} \mathrm{c}$ & 6 & Sudah mengalami perubahan kenaikan tekanan gas \\
\hline 7 & $28,1-42$ & 13,9 & $23,4^{\circ} \mathrm{c}$ & 6 & $\begin{array}{c}\text { Sudah mengalami perubahan kenaikan tekanan gas } \\
\text { as }\end{array}$ \\
\hline 8 & $26,6-43,5$ & 16,9 & $22^{\circ} \mathrm{c}$ & 6 & Sudah mengalami perubahan kenaikan tekanan gas \\
\hline 9 & $22,8-47,2$ & 24,4 & $21,5^{\circ} \mathrm{c}$ & 6 & Sudah mengalami perubahan kenaikan tekanan gas \\
\hline
\end{tabular}

Tabel 7. Data pressure dalam manometr $\mathrm{U}$ setelah penambahan bioktivaktor Em4 sebanyak $2000 \mathrm{ml}$.

\begin{tabular}{|c|c|c|c|c|c|}
\hline Hari & $\begin{array}{c}\text { Pressure Manometer U } \\
\left(\mathrm{Cm} \mathrm{H}_{2} \mathrm{O}\right)\end{array}$ & $\begin{array}{c}\Lambda \mathbf{P} \\
\left(\mathrm{Cm}_{2} \mathrm{O}\right)\end{array}$ & $\begin{array}{c}\text { Suhu Digester } \\
\left({ }^{\circ} \mathrm{c}\right)\end{array}$ & $\mathbf{P h}$ & Ket. \\
\hline 1 & $35-35$ & 0 & $22,5^{\circ} \mathrm{c}$ & 6 & Belum berbau gas \\
\hline 2 & $35-35$ & 0 & $22^{\circ} \mathrm{c}$ & 6 & Belum berbau gas \\
\hline 3 & $35-35$ & 0 & $23,6^{\circ} \mathrm{c}$ & 6 & Belum berbau gas \\
\hline 4 & $35-35$ & 0 & $21,2^{\circ} \mathrm{C}$ & 6 & Sudah ada bau gas \\
\hline 5 & $33,6-36,4$ & 2,8 & $21,4^{\circ} \mathrm{c}$ & 6 & Sudah mengalami perubahan kenaikan tekanan gas \\
\hline 6 & $30,2-39,8$ & 9,6 & $20,5^{\circ} \mathrm{C}$ & 6 & Sudah mengalami perubahan kenaikan tekanan gas \\
\hline 7 & $26,4-43,7$ & 17,3 & $22^{\circ} \mathrm{C}$ & 6,2 & Sudah mengalami perubahan kenaikan tekanan gas \\
\hline 8 & $23-47$ & 24 & $22^{\circ} \mathrm{C}$ & 6,2 & Sudah mengalami perubahan kenaikan tekanan gas \\
\hline 9 & $19,5-50,5$ & 31 & $22^{\circ} \mathrm{C}$ & 6,2 & Sudah mengalami perubahan kenaikan tekanan gas \\
\hline
\end{tabular}

\section{B. Pembahasan}

Faktor-faktor yang mempengaruhi produsi biogas dapat dilihat pada grafik dibawah ini:

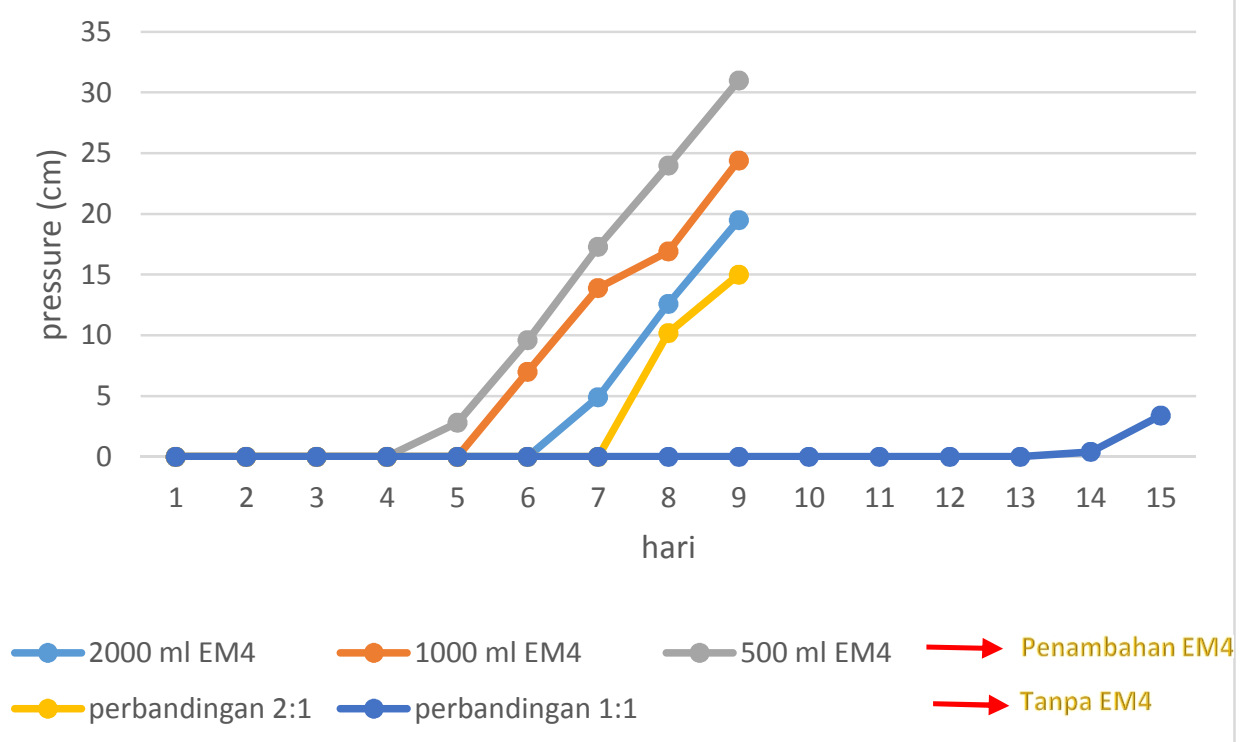

Gambar 2. Grafik perbandingan pressure penambahan EM4 dengan tanpa perbandingan EM4 
Pada gambar 2 menunjukkan bahwa volume pada penambahan $2000 \mathrm{ml}$ EM4 tekanan biogas lebih cepat terbentuk daripada penambahan EM4 sebanyak $500 \mathrm{ml}$ EM4 dan $1000 \mathrm{ml}$ EM4 dimana pada penambahan $2000 \mathrm{ml} \mathrm{EM} 4$ gas akan terbentuk pada hari ke-5 dengan tekanan sekitar $2,8 \mathrm{~cm}_{2} \mathrm{O}$ hingga $31 \mathrm{~cm} \mathrm{H}_{2} \mathrm{O}$ sedangkan pada penambahan $500 \mathrm{ml}$ EM4 gas akan terbentuk pada hari ke-7 dengan tekanan sekitar 4,9 $\mathrm{cm} \mathrm{H}_{2} \mathrm{O}$ hingga $19,5 \mathrm{~cm} \mathrm{H}_{2} \mathrm{O}$ dan Pada penambahan $1000 \mathrm{ml}$ EM4 gas baru akan terbentuk pada hari ke 6 dengan tekanan sekitar $7 \mathrm{~cm}_{2} \mathrm{O}$ hingga $2,4 \mathrm{~cm} \mathrm{H}_{2} \mathrm{O}$.

Pada gambar 2 Menunjukkan bahwa perbandingan air dengan kotoran sapi mempengaruhi laju produksi biogas hal ini terlihat pada grafik diatas dimana perbandingan air dengan kotoran sapi dengan perbandingan 2:1 mengalami pembentukan biogas yang relatif cepat dibandingkan dengan perbandingan 1:1 dan 1:1,5, hal ini dikarenakan biogas mulai terbentuk pada hari ke-4 dan mulai mengalami kenaikan pada hari ke-8 sedangkan pada perbandingan air dengan kotoran sapi dengan perbandingan 1:1 baru mulai terbentuk pada hari ke-6 sedangkan pada perbandingan 1:1,5 baru mulai terbentuk pada hari ke-7 hal ini dapat diketahui dengan mencium adanya gas metana pada katup keluaran pada sambungan kompor.

\section{KESIMPULAN DAN SARAN}

\section{A. Kesimpulan}

Dari hasil analisa berdasarkan data-data yang diperoleh maka dapat diambil kesimpulan antara lain :

1. Pada proses pembentukan biogas dengan perbandingan air dan kotoran sapi dengan perbandingan 1:1 gas akan terbentuk lebih lama daripada perbandingan 2:1 dimana gas baru terbentuk pada hari ke-14 .

2. Dengan adanya penambahan EM4, pembentukan biogas yang dihasilkan lebih cepat daripada tanpa menggunakan EM4. Hal ini menunjukkan EM4 dapat mempercepat proses pembentukan gas metana serta membantu perkembangan bakteri-bakteri dalam pembentukan biogas.

\section{B. Saran}

Setelah menyelesaikan penyusunan tugas akhir ini dapat diajukan saran sebagai berikut:

1. Untuk mencapai produksi biogas yang baik perlu diperhatikan perbandingan kadar air dengan kotoran sapi.

2. Perlu adanya pengecekan secara berkala pada pipa sambungan dan selang sambungan yang tersambung ke digester hal ini dilakukan untuk menghindari terjadinya kebocoran gas.

\section{DAFTAR PUSTAKA}

Adhilaksma, Correy Ananta. 2016. Pengaruh Penggunaan Effective Microorganisms 4 Terhadap Produksi Biogas Dari Tanaman Air Eceng Gondok. Surya University.

Guyup, Mahardhian Dwi Putra,dkk. 2017. Rancang Bangun Reaktor Biogas Tipe Portable Dari Limbah Kotoran Ternak Sapi. Jurnal Ilmiah Rekayasa Pertanian dan Biosistem. Vol.5, No. 1.

Hindi, Norvedo Kms Ridhuan. 2012. Pengaruh Perbandingan Eceng Gondok Dan Kotoran Sapi Terhadap Proses Fermentasi untuk Mendapatkan Energi Biogas. Jurnal Mechanical. Volume 3, Nomor 2.

Maryani Sri. 2016. Potensi Campuran Sampah Sayuran Dan Kotoran Sapi Sebagai Penghasil Biogas. Skripsi, Universitas Islam Negri Maulana Malik Ibrahim. Malang.

Priyadi, Fahad dan Erfan Subiyanta. 2015. Studi Potensi Biogas dari Kotoran Ternak Sapi sebagai Energi Alternatif untuk Penerangan. Universitas 17 Agustus 1945.

Rahman, syamsul dan awaluddin rauf. 2013. IbM Kelompok Usaha Sapi Perah Dan Pengolahan Dangke Di Kabupaten Enrekang. Majalah Aplikasi Ipteks Ngayah: 4(1).

Sunar, Tejo Tsani. 2015. Pengaruh Suhu Dan Konsentrasi Rumen Sapi Terhadap Produksi Biogas Dari Vinase. Tugas Akhir DIII. Jurusan Teknik Kimia. University Negeri Semarang. 
69 Jumadi Tangko, Sonong, Muh. Andi Chaerul S, Junaidi Salam. Analisis Faktor-Faktor Yang Mempengaruhi Produksi Biogas Dari Limbah Ternak Di Kec. Baroko Kab. Enrekang

Wedo, Sasongko. 2010. Produksi Biogas Dari Biomassa Kotoran Sapi Dalam Biodigester Fix Dome Dengan Pengenceran Dan Penambahan Agitasi. Surakarta. Universitas Sebelas Maret.

Yasinta, Dkk. 2014. Pemanfaatan Kotoran Sapi Untuk Bahan Bakar Plt Biogas 80 Kwdi Desa Badaban Kecamatan Ngajum Malang. Jurnal Teknik Pomits. Surabaya.

Yulistiawati, Endang. 2008. Pengaruh Suhu Dan C/N Rasio Terhadap Produksi Biogas Berbahan Baku Sampah Organik Sayuran. Bogor. Institut Pertanian Bogor. 